\title{
MicroRNA-613 represses lipogenesis in HepG2 cells by downregulating LXRa
}

\author{
Dan Zhong1, Yan Zhang ${ }^{1}$, Yi-jun Zeng ${ }^{1}$, Min Gao', Geng-ze Wu², Chang-jiang Hu', Gang Huang ${ }^{1 *}$ \\ and Feng-tian $\mathrm{He}^{1 *}$
}

\begin{abstract}
Background: MicroRNAs (miRNAs) emerge as new important regulators of lipid homeostasis by regulating corresponding genes. MiR-613 is a newly discovered microRNA, of which the biological function is unknown. A recent report has shown that miR-613 downregulates liver $X$ receptor a $(L X R a)$, a ligand-activated nuclear receptor playing an important role in the regulation of lipid metabolism. The purpose of this study is to explore the effect and the molecular basis of miR-613 on lipogenesis in HepG2 cells.

Methods: HepG2 cells were transiently transfected with miR-613 mimic or control microRNA. Real time PCR, Western blot, Luciferase reporter assay and Oil Red O staining were employed to examine the expression of LXRa and its target genes involved in lipogenesis, binding site for miR-613 in 3'-untranslated region (3'-UTR) of LXRa mRNA and lipid droplet accumulation in the cells.

Results: MiR-613 dramatically suppressed the expression of LXRa and its target genes including sterol-regulatory element binding protein 1c (SREBP-1C), fatty acid synthase (FAS), carbohydrate responsive element-binding protein (ChREBP) and acetyl-CoA carboxylase (ACC). Reporter assay showed that miR-613 directly bound to 3'-UTR of LXRa mRNA. Moreover, miR-613 significantly repressed LXRa-induced lipid droplet accumulation in HepG2 cells. Ectopic expression of LXRa without 3'-UTR markedly attenuated the miR-613-mediated downregulation of LXRa's target genes and LXRa-induced lipid droplet accumulation.
\end{abstract}

Conclusions: MiR-613 suppresses lipogenesis by directly targeting LXRa in HepG2 cells, suggesting that miR-613 may serve as a novel target for regulating lipid homeostasis.

Keywords: microRNA-613, Lipogenesis, Liver X receptor a, HepG2 cells

\section{Introduction}

MicroRNAs (miRNAs) are a class of 22 nucleotide non-coding RNAs that regulate genes by binding to the $3^{\prime}$-untranslated region (3'-UTR) of target mRNAs. They are implicated in a variety of diseases including obesity, cancer, atherosclerosis and diabetes [1-3]. Recent studies have shown that miRNAs play an important role in lipid metabolism and several miRNAs have been identified, such as miR-33, miR-122, miR-27, miR-370 [4,5]. MiR-33 regulates the ATP-binding cassette transporters (ABC transporters), $A B C A 1$ and $A B C G 1$, in addition to its role in fatty acid $\beta$-oxidation. MiR-122 regulates several genes that

\footnotetext{
* Correspondence: cqhuanggang@yahoo.com.cn; hefengtian06@yahoo.com. $\mathrm{cn}$

'Department of Biochemistry and Molecular Biology, College of Basic Medical Sciences, Third Military Medical University, Chongqing 400038, China
} Full list of author information is available at the end of the article control fatty acid (FA) and Triglyceride (TG) biosynthesis, such as fatty acid synthase (FAS), acetyl-CoA carboxylase 1 (ACC-1), acetyl-CoA carboxylase 2 (ACC-2), and sterol regulatory element-binding protein 1c (SREBP-1c), as well as genes that regulate fatty acid $\beta$-oxidation, such as carnitine palmitoyltransferase $1 \alpha(\mathrm{CPT} 1 \alpha)$ [6]. Similarly, other miRNAs regulate lipid homeostasis by targeting a variety of lipid metabolism-associated genes.

MiR-613 is a newly discovered miRNA, whose function and molecular basis in the biological process and diseases is incompletely understood. It is reported that miR-613 plays inhibitory role in repressing the Wnt pathway, but its effect on the Wnt-dependent biological processes is unclear. Another report demonstrates the negative role of miR-613 in a feedback loop in the autoregulation of the human LXR $\alpha[7,8]$ without showing its 
subsequent function. Therefore, it is important to clarify the biological function of miR-613 in future.

Lipid homeostasis is regulated by a family of transcription factors including the nuclear hormone receptor LXR $\alpha$ [9]. The molecular mechanism responsible for LXR $\alpha$-mediated lipogenesis has been largely attributed to the dramatic upregulation of the lipogenic genes such as SREBP-1c, FAS, ChREBP and ACC [10-14]. LXR $\alpha$-induced activation of those genes can result in the enhancement of fatty acid synthesis, which contributes to a series of lipogenesis-associated diseases. Therefore, since miR-613 directly targets and decreases the expression of LXR $\alpha$, further studies are needed to determine whether miR-613 can relief LXR $\alpha$-induced lipogenesis via repression of LXR $\alpha$ expression.

In this study, we confirmed that miR-613 directly downregulated LXR $\alpha$ expression at both mRNA and protein levels. Subsequently, LXR $\alpha$-induced lipogenic genes, such as SREBP-1c, FAS, ChREBP and ACC, were inhibited by miR-613, which was abolished by the ectopic expression of LXR $\alpha$ without 3'-UTR. Oil Red O staining revealed that miR-613 reduced LXR $\alpha$-induced lipid droplet accumulation in HepG2 cells, which was also attenuated by ectopic expression of LXR $\alpha$. Our study suggests miR-613 as a critical regulator of lipogenesis.

\section{Materials and methods \\ Reagents}

The miR-613 mimic (5'- AGGAAUGUUCCUUCUUU GCC - $3^{\prime}$ ) and negative control (NC, 5'- UUCUCCGA ACGUGUCACGUTT - $3^{\prime}$ ) were synthesized by Shanghai GenePharma (Shanghai, China). TO901317 and GW3965 were purchased from Sigma Chemical Company (St Louis, MO, USA)

\section{Cell culture}

Human hepatocellular carcinoma cell line HepG2 was purchased from ATCC and cultured in Dulbeco's Modified Eagle's medium (Gibco, Shanghai, China) supplemented with 10\% fetal bovine serum (FBS) (Gibco, Gaithersburg, USA), streptomycin $(100 \mu \mathrm{g} / \mathrm{ml})$ and antibiotics $(100 \mathrm{U} / \mathrm{ml}$ penicillin and $100 \mu \mathrm{g} / \mathrm{ml}$ streptomycin) at $37^{\circ} \mathrm{C}$ in $5 \% \mathrm{CO}_{2}$ humid incubator.

\section{Plasmid construction}

The DNA fragment corresponding to 76-113 nt of human LXR $\alpha$ 3'-UTR containing the miR-613 binding site was synthesized by Sangon Biotech and cloned into pMIR-REPORT vector (Invitrogen) at Sac I and Hind III site downstream of the luciferase gene, and the resulting plasmid was named as pMIR/LXR $\alpha$ MIRE. Similarly, the DNA fragment containing mutations in miR-613 binding site was synthesized and cloned into pMIR-REPORT, and the resulting plasmid was named as pMIR/LXR $\alpha M I R E-m u t$.
The 3'-UTR of the human LXR $\beta$ gene was amplified by PCR with the cDNA of HepG2 cells as template. Purified PCR products digested by Sac I and Hind III (Takara) were cloned into pMIR-REPORT vector, and the resulting plasmid was named as PMIR-LXR $\beta$.

\section{Transient transfections and luciferase assays}

HepG2 cells, grown to $70 \%$ to $80 \%$ confluence, were transiently transfected with luciferase reporters (pMIR-REPORT, pMIR-LXR $\beta, \quad$ pMIR/LXR $\alpha M I R E, \quad p M I R / L X R \alpha M I R E-m u t)$ and miR-613 mimic or mimic NC, using Lipofectamine 2000 according to the manufacturer's instructions (Invitrogen). Transfection efficiency was monitored by cotransfection of pMIR-REPORT- $\beta$-gal (Promega). Luciferase activities were measured using a luciferase assay system (Promega). Transfection experiments were performed 3 times in triplicate. Data was represented as fold induction over reporter gene treated with vehicle alone.

\section{Western blot}

24 hours after transfection, cells were exposed to TO901317 $(5 \mu \mathrm{M})$ for 24 hours. Dimethyl sulfoxide (DMSO, Sigma) was used as controls. Then the whole cell proteins were harvested in lysis buffer $(50 \mathrm{mM}$ Tris-base, $150 \mathrm{mM} \mathrm{NaCl}, 1.0 \mathrm{mM}$ EDTA, 0.1\% SDS, 1\% sodium deoxycholate and $1 \%$ TritonX-100) containing protease inhibitor cocktail. And the protein concentrations were determined using Bradford protein assay reagent (Bio-Rad). Subsequently, the total proteins $(40 \mu \mathrm{g} /$ well $)$ were separated with 10\% SDS-PAGE and transferred to PVDF (polyvinylidene fluoride) membranes (Millipore). After blocked 1 hour with 5\% nonfat milk, the membranes were

Table 1 Primers used for PCR

\begin{tabular}{ll}
\hline Primer name & Sequence \\
\hline LXRa 3'-UTR Forward & $5^{\prime}$-CTGTTCTGTCCCCATATTTCTG-3' \\
LXRa 3'-UTR Reverse & $5^{\prime}$-TCGCAACCCTTGACTCTCT-3' \\
LXRß 3'-UTR Forward & $5^{\prime}$-GACCACCCTCCAGCAGATAG-3' \\
LXRß 3'-UTR Reverse & $5^{\prime}$-AGAGGAAGGCCCTGGTCTC-3' \\
LXRa Forward & $5^{\prime}$-TCAGAGAGGAAGCCAGGATG-3' \\
LXRa Reverse & $5^{\prime}$-ACGGATCTCTGTGGGTTCTG-3' \\
SREBP-1C Forward & $5^{\prime}$-CGACATCGAAGACATGCTTCAG-3' \\
SREBP-1C Reverse & $5^{\prime}$-GGAAGGCTTCAAGAGAGGAGC-3' \\
FAS Forward & $5^{\prime}$-GACATCGTCCATTCGTTTGTG-3' \\
FAS Reverse & $5^{\prime}$-CGGATCACCTTCTTGAGCTCC-3' \\
ChREBP Forward & $5^{\prime}$-AGAGACAAGATCCGCCTGAA-3' \\
ChREBP Reverse & $5^{\prime}$-CTTCCAGTAGTTCCCTCCA-3' \\
ACC Forward & $5^{\prime}$-GCTGCTCGGATCACTAGTGAA-3' \\
ACC Reverse & $5^{\prime}$-TTCTGCTATCAGTCTGTCCAG-3' \\
$\beta$-actin Forward & $5^{\prime}$-GTGAAGGTGACAGCAGTCGGTT-3' \\
$\beta$-actin Reverse & $5^{\prime}$-GAAGTGGGGTGGCTTTAGGA-3'
\end{tabular}


A

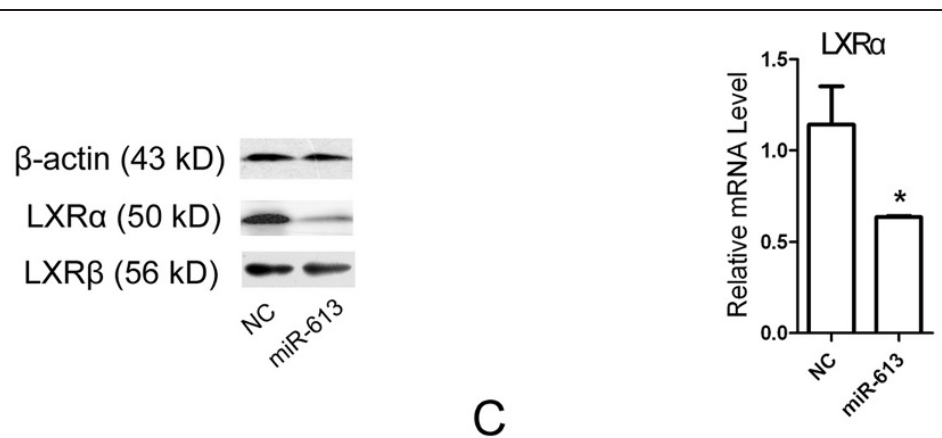

B

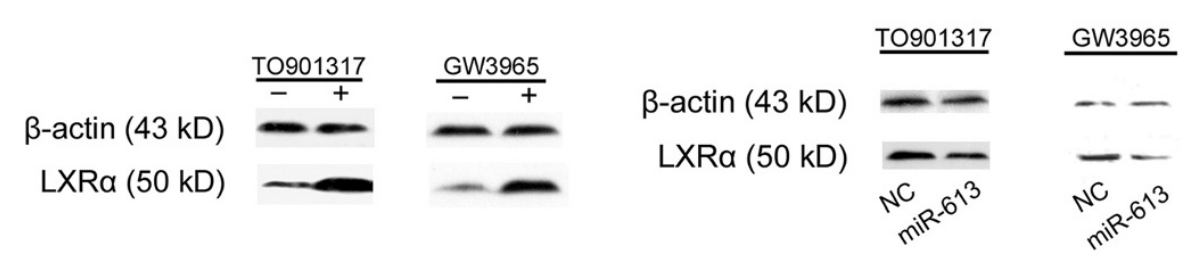

$\mathrm{D}$

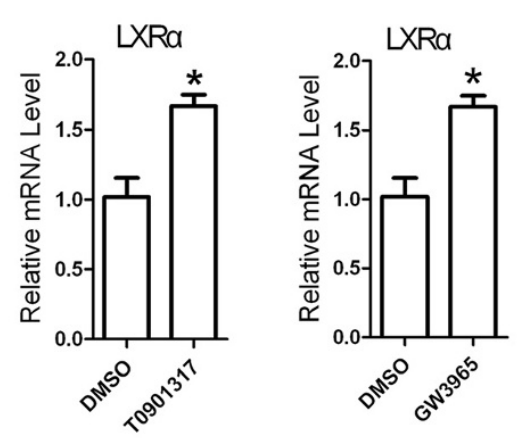

$E$

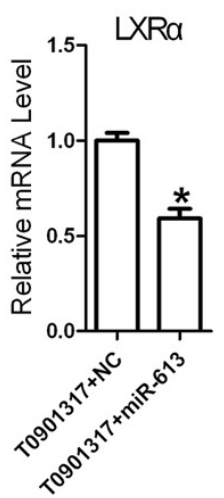

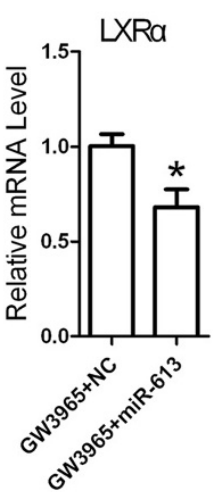

Figure 1 MiR-613 decreases LXRa expression at both mRNA and protein levels. A: HepG2 cells were transfected with 80 nM miR-613 mimic or mimic negative control (NC), after 24 hours total protein was subjected to Western blotting analysis and mRNA expression levels of LXRa were analyzed by real-time quantitative PCR and normalized with $\beta$-actin control. B and D, HepG2 cells were treated with TO901317 (5 HM) or GW3965 $(2 \mu \mathrm{M})$ for 24 hours. Western blot analysis for LXRa protein level (B) and Real-time PCR analysis for LXRa mRNA level (D). C and E, 12 hours after

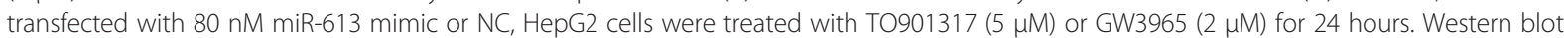
analysis for LXRa protein level (C) and Real-time PCR analysis for LXRa mRNA level (E). The relative level of LXRa expression determined using the $2^{\Delta \Delta C T}$ method. ${ }^{*}, P<0.05$ ( $n=3$ for each group).

incubated with mouse anti-human LXR $\alpha$ antibody (Abcam), or mouse anti-human $\beta$-actin antibody (Santa Cruz Biotechnology) at $4^{\circ} \mathrm{C}$ over night. After washing with TBST, blots were incubated with HRP-labeled rabbit antimouse IgG (Invitrogen) for 1 hour at room temperature. Detection was achieved using enhanced chemiluminescence reagents (Pierce) and exposure to film.

\section{Real-time quantitative reverse transcription-polymerase chain reaction ( $q R T-P C R$ )}

For qRT-PCR, total RNA was extracted from the HepG2 cells using TRIzol and the first-strand cDNA was synthesized using M-MLV reverse transcriptase (Invitrogen) and oligo (dT) primer according to the manufacturer's manual. The expression of LXR $\alpha$, SREBP-1c, FAS, ChREBP and
ACC mRNA was examined by qPCR using SYBR greenbased assays. Relative expressions were calculated with normalization to $\beta$-actin values by using the $2^{-\Delta \Delta \mathrm{Ct}}$ method. The sequences of primers used for quantitative PCR analysis were shown in Table 1.

\section{Oil Red O staining}

Oil Red $\mathrm{O}$ stock solution was prepared in isopropanol $(0.25 \mathrm{~g} / 100 \mathrm{ml})$ and heated to $100^{\circ} \mathrm{C}$ for $10 \mathrm{~min}$. TO901317-treated cells were fixed with $4 \%$ paraformaldehyde for $30 \mathrm{~min}$ and washed with PBS. Then cells were soaked in $60 \%$ Oil Red O stock solution diluted by distilled water for $30 \mathrm{~min}$. Stained cells were washed with PBS until the background became clear. Images were captured with fluorescence microscopy (Olympus). 


\section{Statistical analysis}

All data are expressed as means \pm SD unless otherwise stated. Comparisons between two groups were made with unpaired Student's t-tests. Non-parametric comparisons between three or more groups were made with ANOVA followed by Kruskal-Wallis post hoc analysis. In all cases, $P<0.05$ was considered statistically significant.

\section{Results}

MiR-613 reduces $L X R a$ expression at both mRNA and protein levels

It has been reported that miR-613 negatively regulated the expression and activity of endogenous LXR $\alpha$. To examine whether these results are obtainable under our experimental conditions, HepG2 cells were transfected with miR-613 mimic or negative control (NC). Western blot and real-time PCR analysis showed that endogenous LXR $\alpha$ expression was repressed by miR-613 at both protein and mRNA levels (Figure 1A), while LXR $\beta$ expression was not affected, which suggested that miR-613 effect was specific for LXR $\alpha$. Furthermore, as LXR $\alpha$ activation leads to the lipogenesis in liver, we determined whether miR-613 could inhibit agonist-induced LXR $\alpha$ expression. Treatment with either TO901317 or GW3965 induced mRNA and protein expression of LXR $\alpha$ (Figure 1B and D), which was repressed by miR-613 (Figure 1C and E). Similarly, miR-613 suppressed TO901317-induced LXR $\alpha$ expression at both mRNA and protein levels in L02 cells (Additional file 1: Figure S1). These results demonstrated that miR-613 downregulated both endogenous and agonist-induced LXR $\alpha$ expression.

\section{MiR-613 directly targets LXRa 3'-UTR}

We also found the binding site for miR-613 on LXR $\alpha$ 3'-UTR by TargetScan analyses (Figure 2A). Cotransfection with miR-613 mimic resulted in a decrease of the luciferase activity of pMIR/LXR $\alpha$ MIRE plasmid containing the LXR $\alpha M I R E 613$, while the luciferase activity of pMIR/ LXR $\alpha M I R E-m u t$ plasmid containing mutations in miR-613 recognition site was not affected (Figure 2B). Moreover, cotransfection with miR-613 mimic had no effect on the luciferase activity of pMIR-LXR $\beta$ plasmid containing the LXR $\beta$ 3'-UTR (Figure 2C). These results revealed that miR-613 directly targeted LXR $\alpha$ on its $3^{\prime}$-UTR, but not LXR $\beta$.

\section{A \\ miR-613 \\ 3' CCGUUUCUUCCUUGUAAGGU \\ hLXRa 3'UTR \\ | || || || ||| \\ hLXRa 3'UTR-M 5' \\ 80 GAGAAGGGCAACACGUAAUGGGAG 103}

B

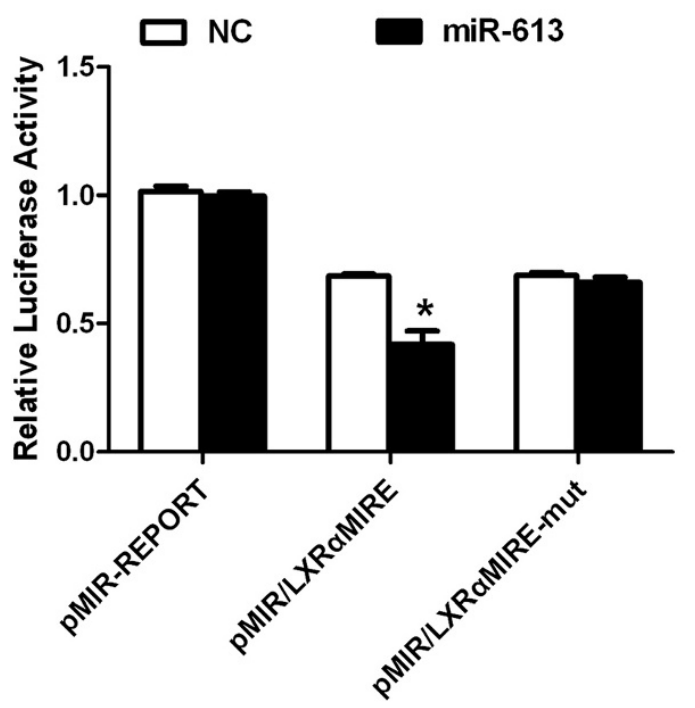

C LXRß 3' UTR

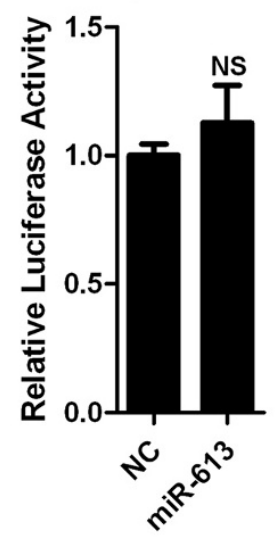

Figure 2 MiR-613 directly targets LXRa 3'-UTR. A: A putative binding site of miR-613 in the 3'-UTR of LXRa mRNA and mutated nucleotide residues are shown in red and italics. B: pMIR/LXRaMIRE or pMIR/LXRaMIRE-mut was cotransfected with 80 nM miR-613 mimic or NC into HepG2 cells. C, PMIR-LXRß was transiently cotransfected with $80 \mathrm{nM}$ indicated RNA oligonucleotides into HepG2 cells. Luciferase assay was conducted after 24 hours. The data was the firefly luciferase activities normalized with the $\beta$-galactosidase activities. ${ }^{*}, P<0.05$ ( $n=3$ for each group). 

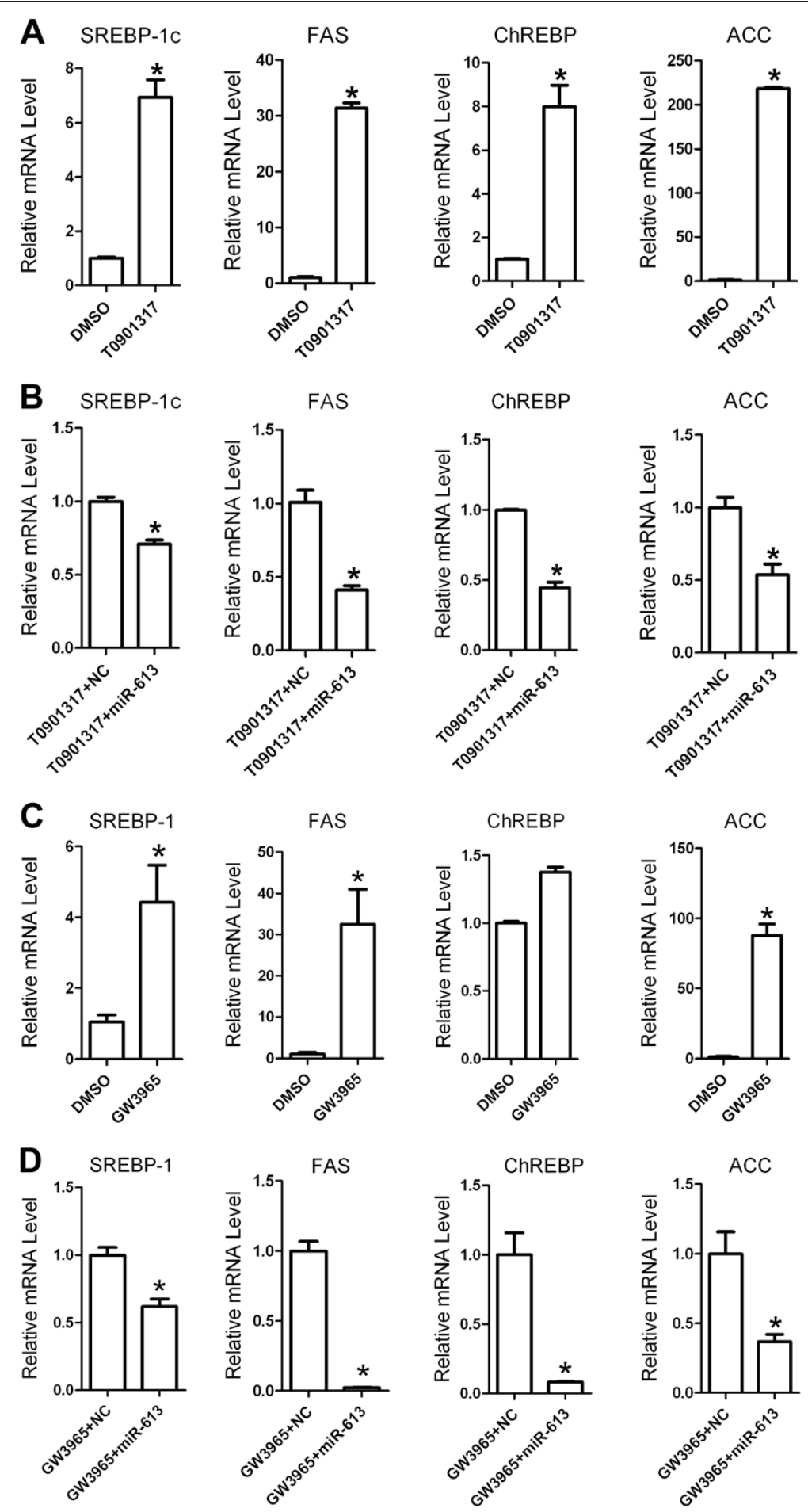

Figure 3 MiR-613 suppresses LXRa-induced lipogenic genes. A and B: HepG2 cells were treated with TO901317 (5 $\mu$ M) or GW3965 (2 $\mu$ M) for 24 hours. Real-time PCR analysis for SREBP-1c, FAS, ChREBP and ACC mRNA level. C and D, after 12 hours transfected with $80 \mathrm{nM}$ miR-613 mimic or NC, HepG2 cells were treated with TO901317 $(5 \mu \mathrm{M})$ or GW3965 (2 $\mu \mathrm{M})$ for 24 hours. Real-time PCR analysis for SREBP-1C, FAS, ChREBP and ACC mRNA level. The relative level of lipogenic gene expression determined using the $2^{-{ }^{\Delta C T}}$ method. ${ }^{*}, P<0.05$ ( $n=3$ for each group). 


\section{MiR-613 suppresses lipogenic genes through downregulation of LXRa}

Activation of LXR $\alpha$ has been shown to promote the hepatic lipogenesis by increasing the expression of lipogenic genes. We therefore determined the effect of miR-613 on LXR $\alpha$ induced genes related with lipogenesis. As is shown in Figure 3A and C, both TO901317 and GW3965 successfully upregulated the mRNA expression of LXR $\alpha$-targeted lipogenic genes, such as SREBP-1c, FAS, ChREBP and ACC. Moreover, miR-613 significantly decreased LXR $\alpha$-induced expression of those genes (Figure 3B and D). Furthermore, miR-613 also downregulated these TO901317-induced target genes in L02 cells (Additional file 2: Figure S2). To examine whether miR-613 repressed lipogenic genes via downregulation of LXR $\alpha$, HepG2 cells were cotransfected with miR-613 mimic and LXR $\alpha$-expressing plasmid pEXLXR $\alpha$ (without $3^{\prime}$-UTR in LXR $\alpha$ mRNA). As expected, ectopic expression of LXR $\alpha$ reversed the inhibitory effect of miR-613 on lipogenic genes (Figure 4). These results suggested that miR-613 repressed lipogenic genes in an LXR $\alpha$-dependent manner.

\section{MiR-613 reduces lipid droplet accumulation through downregulation of LXRa in HepG2 cells}

To further investigate the function of miR-613, we determined whether miR-613 could decrease LXR $\alpha$-induced accumulation of lipid droplets in HepG2 cells. 12 hours after transfected with miR-613 mimic, HepG2 cells were treated with TO901317 for 24 hours, then Oil Red O staining was performed. The lipid droplet accumulation of cells transfected with miR-613 mimic was markedly reduced compared with negative controls (Figure 5A). However, ectopic expression of LXR $\alpha$ (without $3^{\prime}$-UTR) attenuated the suppression of lipid droplet accumulation by miR-613 (Figure 5B). These results suggested that miR-613 might function as an anti-lipogenesis miRNA in HepG2 cells.

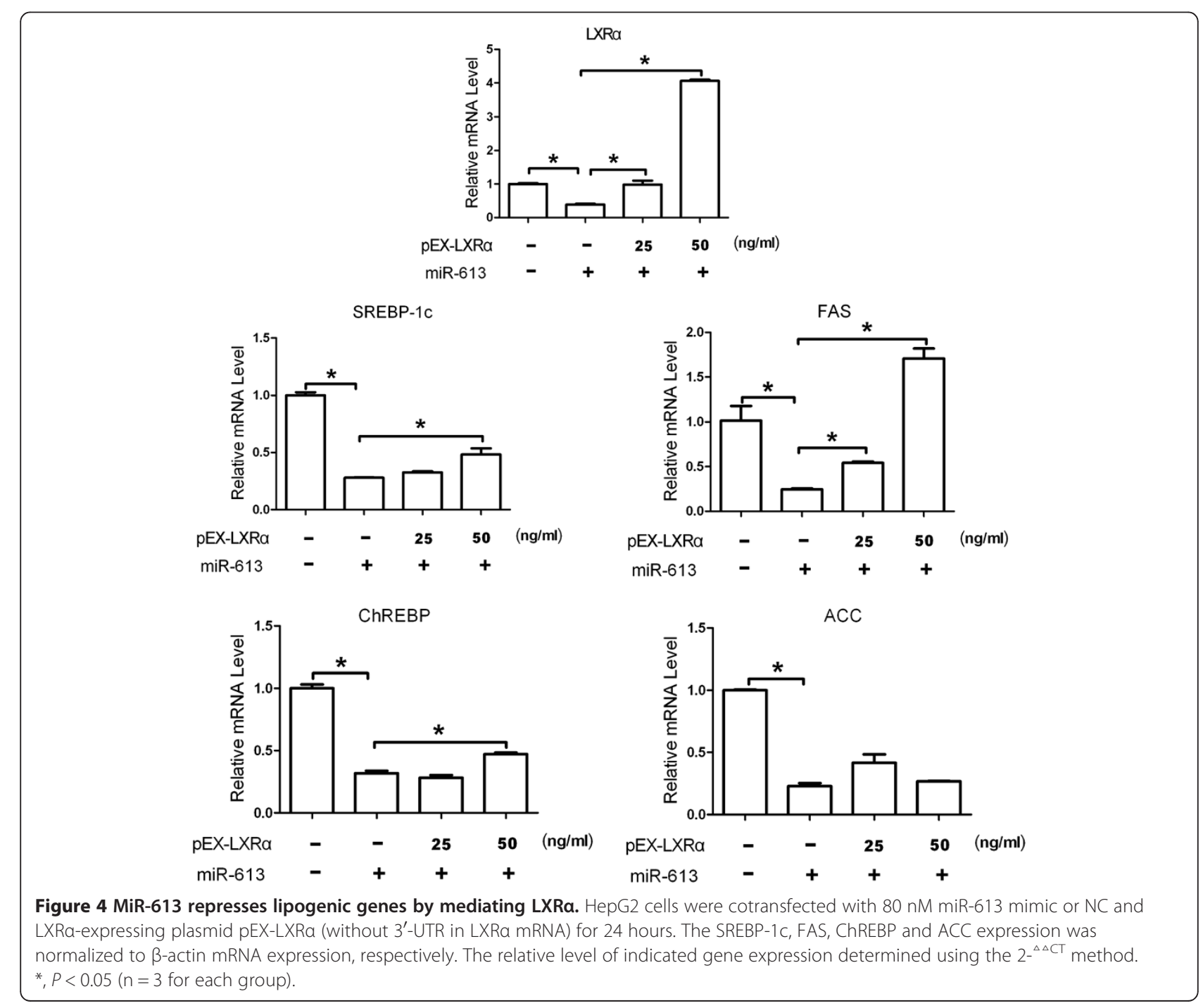




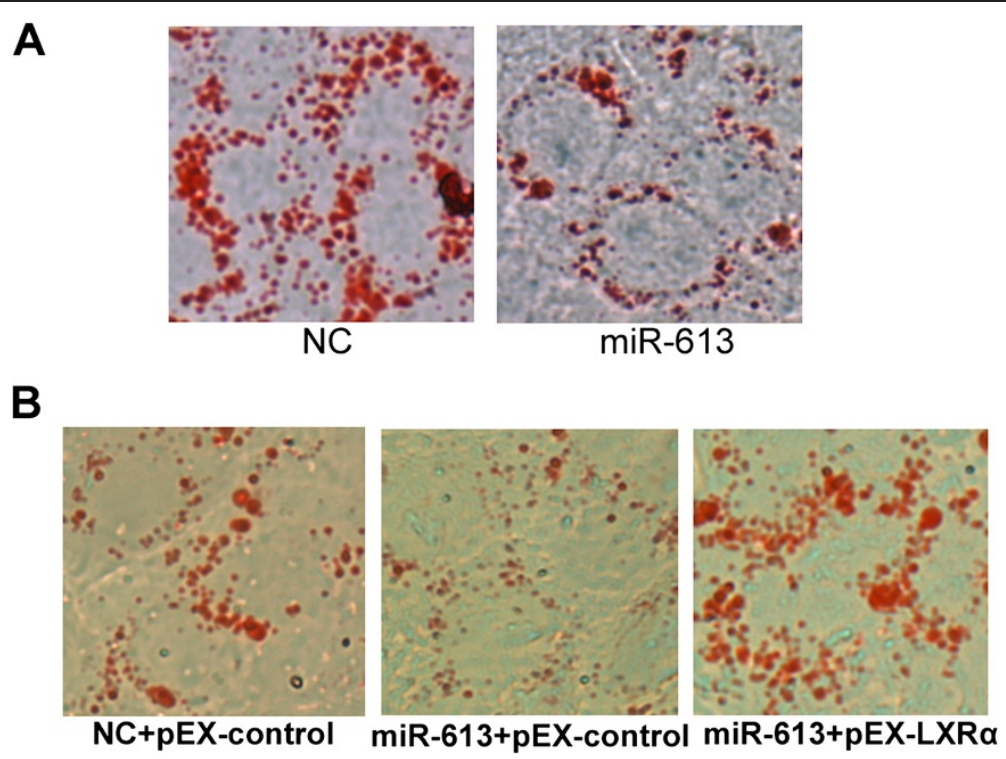

Figure 5 MiR-613 represses lipogenesis by mediating LXRa. The lipid synthesis was shown by Oil Red O staining (400X). A: After 12 hours

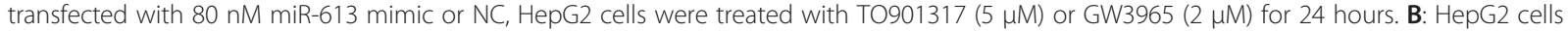
were cotransfected with 80 nM miR-613 mimic or NC and LXRa-expressing plasmid pEX-LXRa for 24 hours. Results represent 3 independent experiments.

\section{Discussion}

With the development of our modern society, the people's lifestyle is characterized by an overabundant supply of food rich in energy and little physical activity, which enhance the lipid accumulation leading to a series of lipogenesis-associated diseases including dyslipidemia, hypertension, heart disease and fatty liver [15-18]. Therefore, the negative regulation of lipid synthesis may help with the treatment for lipid metabolism disorders. In our present study, we found miR-613 as an antilipogenesis miRNA through the suppression of LXR $\alpha$, which provided a novel effective target for the therapy of lipogenesis-associated diseases.

From the recent studies, our understanding of miR613 is extremely limited. It is reported that miR-613 is involved in the auto-regulation of LXR $\alpha$ by directly targeting LXR $\alpha$ 3'-UTR, but its biological function isn't mentioned. Here, we first revealed the anti-lipogenic function of miR-613. It repressed expression of lipogenic genes and accumulation of lipid droplets in HepG2 cells by suppression of $L X R \alpha$, which suggested the potential use of miR-613 as a therapeutic tool in lipogenesisassociated diseases, such as hepatic steatosis. Another report has demonstrated that miR-613 has inhibitory effect on the activity of the Wnt pathway by targeting the pathway upstream of Axin or active $\beta$-catenin. However, there is no evidence showing the effect of miR-613 on Wnt-dependent human cancer cells and the precise and direct targets of miR-613 [7,8]. Consequently, both the effects of miR-613 on Wnt-dependent cell proliferation and its other biological functions remain to be clarified. Moreover, for one miRNA can target more than one gene, further studies are needed to establish target landscape of miR-613.

MiRNAs regulate gene expression by binding mRNAs at $3^{\prime}$-UTR $/ 5^{\prime}$-UTR or open reading frame (ORF), leading to translational repression and mRNA cleavage [19-21]. Though the targeting site for miR-613 at LXR $\alpha 3^{\prime}$-UTR has been uncovered, further study is needed to find out whether miR-613 can regulate LXR $\alpha$ by binding at 5 '-UTR or ORF of LXR $\alpha$ mRNA. Unfortunately, bioinformatic analysis showed no possible binding site for miR-613 at ORF of LXR $\alpha$ mRNA, which might not be the mechanism by which miR-613 regulates $L X R \alpha$.

Increasing genes are shown to be in the control of LXR $\alpha$, but the regulation of LXR $\alpha$ itself is not fully understood. It has been reported that peroxisome proliferator-activated receptor (PPAR), retinoid-related orphan receptor (ROR), protein kinase $\mathrm{C}$ (PKC) and oxysterol binding protein related protein $1 \mathrm{~S}$ (ORP1S) can potentially regulate the activation of LXR $\alpha$ [22-25]. In addition, the epigenic modification such as phosphorylation and SUMOylation, may affect LXR $\alpha$ actions [26,27]. Thus there are opportunities for miR-613 to indirectly regulate LXR $\alpha$ through the modulation of its upstream regulators such as PPAR, ROR and PKC. Similarly, although we demonstrated that miR-613 indirectly affected the expression of lipogenic genes, it needs to be examined whether the miRNA could directly target these lipogenic genes. 


\section{Conclusions}

In our present study, we demonstrated that miR-613 function as a novel modulater participating in lipid metabolism. It repressed lipogenic genes including SREBP-1c, FAS, ChREBP and ACC by suppression of LXR $\alpha$ expression. Subsequently, the accumulation of lipid droplets in HpG2 cells was significantly decreased by miR-613. These findings suggested that miR-613 was a potential target for the therapy of lipid dysfunction associated diseases.

\section{Additional files}

Additional file 1: Figure S1. MiR-613 decreases TO901317-activated LXRa expression at both mRNA and protien levels in L02 cells. 12 hours after transfected with $80 \mathrm{nM}$ miR-613 mimic or NC, L02 cells were treated with TO901317 (5 $\mu \mathrm{M})$ for 24 hours. Real-time PCR analysis for LXRa mRNA level (A) and Western blot analysis for LXRa protein level (B). The relative level of LXRa expression determined using the $2^{-{ }^{\Delta C T}}$ method. * $P<0.05$ ( $n=3$ for each group).

Additional file 2: Figure S2. MiR-613 suppresses LXRa-induced lipogenic genes in L02 cells. A, L02 cells were treated with TO901317 $(5 \mu \mathrm{M})$ for 24 hours. Real-time PCR analysis for SREBP-1C, FAS, ChREBP and ACC mRNA level. B, after 12 hours transfected with $80 \mathrm{nM}$ miR-613 mimic or NC, L02 cells were treated with TO901317 (5 $\mu \mathrm{M})$ for 24 hours. Real-time PCR analysis for SREBP-1c, FAS, ChREBP and ACC mRNA level. The relative level of lipogenic gene expression determined using the $2^{\Delta \Delta C T}$ method. *, $P<0.05$ ( $n=3$ for each group).

\section{Abbreviations}

LXRa/ $\beta$ : Liver $X$ receptor a/ $\beta$; miRs: MicroRNAs; SREBP-1c: Sterol-regulatory element binding protein 1c; FAS: Fatty acid synthase; ChREBP: Carbohydrate responsive element-binding protein; ACC: Acetyl-CoA carboxylase; RXRa: Retinoid X receptor a; PPAR: Peroxisome proliferator-activated receptor; ROR: Retinoid-related orphan receptor; PKC: Protein kinase $C_{\text {; }}$ ORP1S: Oxysterol binding protein related protein 1S; CPT1a: Carnitine palmitoyltransferase $1 a$.

\section{Competing interests}

The authors declare that they have no competing interests.

\section{Authors' contributions}

DZ was responsible for all aspects of the project, including study design, experiments, statistical analysis, and manuscript preparation. FTH and GH were involved in the co-design of the work as well as the draft of the manuscript. YJZ carried out the cell studies. GZW and CJH participated in the molecular studies. YZ and MG carried out analytical work and contributed in drafting the manuscript. All authors read and approved the final manuscript.

\section{Authors' information}

DZ is a Ph.D. student; FTH, GH, YZ and MG are Ph.D. YJZ is a medical scientific researcher. GZW and $\mathrm{CJH}$ are Ph.D. students.

\section{Acknowledgements}

This work was supported by the National Natural Science Foundation of China (No.81273226, 81102276) and the Natural Science Foundation Project of Chongqing (No. cstc2012jjA10054).

\section{Author details}

'Department of Biochemistry and Molecular Biology, College of Basic Medical Sciences, Third Military Medical University, Chongqing 400038, China. ${ }^{2}$ Department of cardiology, Daping Hospital, Third Military Medical University, Chongqing 400042, China.
Received: 4 December 2012 Accepted: 28 February 2013

Published: 8 March 2013

\section{References}

1. Fernandez-Valverde SL, Taft RJ, Mattick JS: MicroRNAs in beta-cell biology, insulin resistance, diabetes and its complications. Diabetes 2011, 60(7):1825-1831.

2. David S, Meltzer SJ: MicroRNA involvement in esophageal carcinogenesis. Curr Opin Pharmacol 2011, 11(6):612-616.

3. Zhang C: MicroRNA and vascular smooth muscle cell phenotype: new therapy for atherosclerosis? Genome Med 2009, 1(9):85.

4. Sacco J, Adeli K: MicroRNAs: emerging roles in lipid and lipoprotein metabolism. Curr Opin Lipidol 2012, 23(3):220-225.

5. Fernandez-Hernando C, Suarez Y, Rayner KJ, Moore KJ: MicroRNAs in lipid metabolism. Curr Opin Lipidol 2011, 22(2):86-92.

6. Moore K, Rayner KJ, Suarez Y, Fernandez-Hernando C: The role of microRNAs in cholesterol efflux and hepatic lipid metabolism. Annu Rev Nutr 2011, 31:49-63.

7. Anton $R$, Chatterjee SS, Simundza J, Cowin P, Dasgupta R: A systematic screen for micro-RNAs regulating the canonical Wnt pathway. PLoS One 2011, 6(10):e26257.

8. Ou Z, Wada T, Gramignoli R, Li S, Strom SC, Huang M, Xie W: MicroRNA hsa-miR-613 targets the human LXRalpha gene and mediates a feedback loop of LXRalpha autoregulation. Mol Endocrinol 2011, 25(4):584-596.

9. Repa JJ, Mangelsdorf DJ: The role of orphan nuclear receptors in the regulation of cholesterol homeostasis. Annu Rev Cell Dev Biol 2000, 16:459-481.

10. Chen G, Liang G, Ou J, Goldstein JL, Brown MS: Central role for liver $X$ receptor in insulin-mediated activation of Srebp-1c transcription and stimulation of fatty acid synthesis in liver. Proc Natl Acad Sci U S A 2004, 101(31):11245-11250.

11. Cha JY, Repa JJ: The liver $X$ receptor (LXR) and hepatic lipogenesis. The carbohydrate-response element-binding protein is a target gene of LXR. J Biol Chem 2007, 282(1):743-751.

12. Schultz JR, Tu H, Luk A, Repa JJ, Medina JC, Li L, Schwendner S, Wang S, Thoolen M, Mangelsdorf DJ, et al: Role of LXRs in control of lipogenesis. Genes Dev 2000, 14(22):2831-2838.

13. Talukdar S, Hillgartner FB: The mechanism mediating the activation of acetyl-coenzyme $\mathrm{A}$ carboxylase-alpha gene transcription by the liver $\mathrm{X}$ receptor agonist T0-901317. J Lipid Res 2006, 47(11):2451-2461.

14. Yu H, Wu J, Yang M, Guo J, Zheng L, Peng M, Zhang Q, Xiang Y, Cao J, Shen $\mathrm{W}$ : Involvement of liver $\mathrm{X}$ receptor alpha in histone modifications across the target fatty acid synthase gene. Lipids 2012, 47(3):249-257.

15. Spiegelman BM, Flier JS: Obesity and the regulation of energy balance. Cell 2001, 104(4):531-543.

16. Kahn BB, Flier JS: Obesity and insulin resistance. J Clin Invest 2000, 106(4):473-481.

17. Berge KE, von Bergmann K, Lutjohann D, Guerra R, Grundy SM, Hobbs HH, Cohen JC: Heritability of plasma noncholesterol sterols and relationship to DNA sequence polymorphism in ABCG5 and ABCG8. J Lipid Res 2002, 43(3):486-494

18. Kang JH, Cho Kl, Kim SM, Lee JY, Kim JJ, Goo JJ, Kim KN, Jhi JH, Kim DJ, Lee $\mathrm{HG}$, et al: Relationship between Nonalcoholic Fatty Liver Disease and Carotid Artery Atherosclerosis Beyond Metabolic Disorders in Non-Diabetic Patients. J Cardiovasc Ultrasound 2012, 20(3):126-133.

19. Montenegro D, Romero R, Kim SS, Tarca AL, Draghici S, Kusanovic JP, Kim JS, Lee DC, Erez O, Gotsch F, et al: Expression patterns of microRNAs in the chorioamniotic membranes: a role for microRNAs in human pregnancy and parturition. J Pathol 2009, 217(1):113-121.

20. Spriggs KA, Bushell M, Willis AE: Translational regulation of gene expression during conditions of cell stress. Mol Cell 2010, 40(2):228-237.

21. Kang JG, Majerciak V, Uldrick TS, Wang X, Kruhlak M, Yarchoan R, Zheng ZM: Kaposi's sarcoma-associated herpesviral IL- 6 and human IL- 6 open reading frames contain miRNA binding sites and are subject to cellular miRNA regulation. J Pathol 2011, 225(3):378-389.

22. Kidani $Y$, Bensinger SJ: Liver $X$ receptor and peroxisome proliferator-activated receptor as integrators of lipid homeostasis and immunity. Immunol Rev 2012, 249(1):72-83. 
23. Wada $T$, Kang HS, Jetten AM, Xie W: The emerging role of nuclear receptor RORalpha and its crosstalk with LXR in xeno- and endobiotic gene regulation. Exp Biol Med (Maywood) 2008, 233(10):1191-1201.

24. Delvecchio CJ, Capone JP: Protein kinase $C$ alpha modulates liver $X$ receptor alpha transactivation. J Endocrinol 2008, 197(1):121-130.

25. Lee $S$, Wang PY, Jeong $Y$, Mangelsdorf DJ, Anderson RG, Michaely P: Sterol-dependent nuclear import of ORP1S promotes LXR regulated trans-activation of apoE. Exp Cell Res 2012, 318(16):2128-2142.

26. Torra IP, Ismaili N, Feig JE, Xu CF, Cavasotto C, Pancratov R, Rogatsky I, Neubert TA, Fisher EA, Garabedian MJ: Phosphorylation of liver X receptor alpha selectively regulates target gene expression in macrophages. Mol Cell Biol 2008, 28(8):2626-2636.

27. Lee JH, Park SM, Kim OS, Lee CS, Woo JH, Park SJ, Joe EH, Jou I: Differential SUMOylation of LXRalpha and LXRbeta mediates transrepression of STAT1 inflammatory signaling in IFN-gamma-stimulated brain astrocytes. Mol Cell 2009, 35(6):806-817.

doi:10.1186/1476-511X-12-32

Cite this article as: Zhong et al:: MicroRNA-613 represses lipogenesis in HepG2 cells by downregulating LXRa. Lipids in Health and Disease 2013 12:32.

\section{Submit your next manuscript to BioMed Central and take full advantage of:}

- Convenient online submission

- Thorough peer review

- No space constraints or color figure charges

- Immediate publication on acceptance

- Inclusion in PubMed, CAS, Scopus and Google Scholar

- Research which is freely available for redistribution 